17. Kuter B, Matthews $H$, Shinefield $H$, Black $S$, Dennehy $P$, Watson $B$, et al. Ten year follow-up of healthy children who received one or two injections of varicella vaccine. Pediatr Infect Dis J 2004;23:132-7.

18. Seward JF, Watson BM, Peterson CL, Mascola L, Pelosi JW, Zhang JX, et al. Varicella disease after introduction of varicella vaccine in the United States, 1995-2000. JAMA 2002;287:606-11.

Conflict of interest: none declared

\section{Self-test questions}

The following statements are either true or false (answers on page 23)

1. A skin rash may occur three weeks after an injection of varicella zoster virus vaccine.

2. Adults who request vaccination against varicella zoster virus are recommended to first have a blood test to check their immunity to the virus.

\title{
Letters
}

Letters, which may not necessarily be published in full, should be restricted to not more than 250 words. When relevant, comment on the letter is sought from the author. Due to production schedules, it is normally not possible to publish letters received in response to material appearing in a particular issue earlier than the second or third subsequent issue.

\section{Tumour necrosis factor alpha inhibitors for the treatment of adult rheumatoid arthritis}

Editor, - Professor McColl is to be congratulated for his admirable review ofTNF-targeted antibodies (Aust Prescr 2004;27:43-6). These protein therapies may still need to be used as synergists with well-tried drugs such as methotrexate. They are very expensive and a real burden to both the Pharmaceutical Benefits Scheme (PBS) and to rheumatologists, who must provide much supportive data justifying the patient's need. Some of the criteria for their use may be suspect. ${ }^{1}$

Two of these antibodies can bind cell-boundTNF, perhaps inducing apoptosis of the TNF-producing cells. In the long term, this may compromise natural defences against comorbidities, for example tumours, tuberculosis. (The third drug (etanercept) binds TNF after release from the cells.)

There are much cheaper drugs for controlling TNF production such as thalidomide and oxpentifylline (pentoxifylline). ${ }^{2}$ Thalidomide may be in the 'too-hard basket', but oxpentifylline has been used for more than 30 years to treat poor circulation. ${ }^{3}$ Oxpentifylline is a proven alternative to steroids for controlling granulomatous inflammation in Hansen's disease. ${ }^{4,5}$ So its safety is not an issue. Its short half-life ${ }^{3}$ permits rapid suspension of use should compromising situations such as infections arise. For optimal efficacy in treating chronic inflammation oxpentifylline may have to be used synergistically. ${ }^{6}$ One month's supply (400 mg tds) costs approximately $\$ 80$ in Australia.

You will not read much about company-sponsored trials as the drug is out of patent and regulatory agencies do not favour drug combinations. The big question is whether support can be found for clinical trials of non-protein TNF-blockers. Positive outcomes might be much reduced costs to the PBS and widening the availability of TNF inhibition therapy.

\section{Michael Whitehouse}

Therapeutics Research Unit

Department of Medicine

Princess Alexandra Hospital

Woolloongabba, Qld

\section{References}

1. Lu CY, Day RO, Williams KM. Lack of evidence for an association between rheumatoid factor status and clinical response in patients with rheumatoid arthritis treated with TNF alpha inhibitors. Intern Med J 2004;34:S104.

2. Strieter RM, Remick DG, Ward PA, Spengler RN, Lynch JP, Larrick $\mathrm{J}$, et al. Cellular and molecular regulation of tumor necrosis factor-alpha production by pentoxifylline. Biochem Biophys Res Commun 1988;155:1230-6.

3. Ward A, Clissold SP. Pentoxifylline. A review of its pharmacodynamic and pharmacokinetic properties, and its therapeutic efficacy. Drugs 1987;34:50-97.

4. Nery JA, Perisse AR, Sales AM, Vieira LM, Souza RV, Sampaio EP, et al. The use of pentoxifylline in the treatment of type 2 reactional episodes in leprosy. Indian J Lepr 2000;72:457-67.

5. Sampaio EP, Moraes MO, Nery JA, Santos AR, Matos HC, Sarno EN. Pentoxifylline decreases in vivo and in vitro tumor necrosis factor-alpha (TNF-alpha) production in lepromatous leprosy patients with erythema nodosum leprosum (ENL). Clin Exp Immunol 1998;111:300-8.

6. Whitehouse MW. (Point of view) Anti-TNF- $\alpha$ therapy for chronic inflammation: reconsidering pentoxifylline as an alternative to therapeutic protein drugs. Inflammopharmacology 2004;12:223-7. 
Professor G. McColl, the author of the article, comments:

I agree that the presence or absence of rheumatoid factor in patients treated with TNF inhibitors may not alter the likelihood of them responding. Studies subsequent to those used for the submission to the Australian Pharmaceutical Benefits Advisory Committee have shown that rheumatoid factor may not be a response-modifier, but further analysis of this information is required. I also agree about the increase of infectious risk when using TNF inhibitors and all clinicians using these agents must remain vigilant with regard to this risk.

Oxpentifylline and thalidomide do have anti-TNF effects, but the magnitude of their biological effect in rheumatoid arthritis appears modest, and certainly less than the TNF inhibitors described in my review, even when used in combination with methotrexate. ${ }^{1,2,3,4}$ Complications of thalidomide, especially neuropathy, also limit its clinical applicability in rheumatoid arthritis. The final comment about testing medications not protected by patent is reasonable and clearly work in this area will have to be investigatordriven and supported by institutions such as the National Health and Medical Research Council or the National Institutes of Health.

\section{References}

1. Dubost JJ, Soubrier M, Ristori JM, Beaujon G, OualidT, Bussiere JL, Sauvezie B. An open study of the anti-TNF alpha agent pentoxifylline in the treatment of rheumatoid arthritis. Rev Rhum Engl Ed 1997;64:789-93.

2. Huizinga TW, Dijkmans BA, van der Velde EA, van de Pouw Kraan TC, Verweij CL, Breedveld FC. An open study of pentoxyfylline and thalidomide as adjuvant therapy in the treatment of rheumatoid arthritis. Ann Rheum Dis 1996;55:833-6.

3. Scoville CD. Pilot study using the combination of methotrexate and thalidomide in the treatment of rheumatoid arthritis. Clin Exp Rheumatol 2001;19:360-1.

4. Gutiérrez-Rodríguez $\mathrm{O}$, Starusta-Bacal $\mathrm{P}$, GutiérrezMontes O.Treatment of refractory rheumatoid arthritis: the thalidomide experience. J Rheumatol 1989;16:158-63.

\section{Dispensing practices and labelling of drugs}

Editor, - As a consumer of various prescription drugs I am concerned at the dispensing practices of some pharmacists with regard to exterior packaging of jars containing drugs.

For example, one of the drugs I regularly take is methotrexate which is packed into a small plastic jar, which is then packed inside a box. The extra packaging (that is, the box) is usually discarded and the jar containing the tablets is kept in the cabinet. What concerns me is that the pharmacist's label with the doctor's instructions for use is too often placed on the exterior box!
These are not blister packs, but jars within boxes. Other drugs I take that are dispensed in the same manner are leflunomide and calcium folinate. How many other drugs are dispensed in this manner?

Can you understand my concern regarding the possible mismanagement of drugs when labels are not present on jars? Is this standard practice for dispensing, or do the guidelines need to be reviewed?

Vivienne McCullagh

Kellyville, NSW

\section{Ms Kerry Deans, Chief Executive Officer, Pharmaceutical Society of Australia, comments:}

Pharmacists are required by State legislation to place dispensing labels on medicine containers which are usually understood to be the primary container. There are exceptions on some types of medicines, but I do not believe these are relevant in this case.

As you would be aware, there is also much other mandatory information (e.g. trade name, active ingredient name, dose form, strength, quantity, expiry date, warning statements and other regulatory requirements) that the manufacturer must provide on the original label on the container of prescription medicines.

There is a general expectation that pharmacists should not obscure any vital information on the manufacturer's label when affixing the pharmacy dispensing label. At times this presents a challenge, particularly with small containers, and pharmacists may opt to 'flag' the label (where part of the label is folded back onto itself) or place the label on the outer box or packaging.

In such cases it would be reasonable to expect the pharmacist to provide verbal reinforcement of the key messages as well as perhaps an explanation of why the dispensing label has not been placed on the primary container.

In some instances it may also be beneficial if the patient was able to communicate their preference to assist with safe and appropriate administration and quality use of medicines.

\section{Changes to the shelf-life of thyroxine}

Editor, - In June 2003 the Therapeutic Goods Administration (TGA) instructed Sigma Pharmaceuticals to reduce the shelf-lives of Oroxine and Eutroxsig - the Australian brands of thyroxine - from 24 months to 12 months (with refrigeration). This was in light of evidence that their potency was reduced at the end of their shelf-life. Sigma, following consultation with the TGA, has been able to extend the shelflife of these products to 18 months (with refrigeration), with a maximum unrefrigerated period of 4 weeks (below $25^{\circ} \mathrm{C}$ ). 
While Thyroid Australia understands and appreciates theTGA's efforts to ensure the potency of thyroxine for the entirety of its shelf-life, we view the change to refrigeration as a retrograde step in the treatment of hypothyroidism in Australia.

We are concerned that this change could have a negative impact on compliance. In addition, it seems Australia is the only country where thyroxine tablets require refrigeration. In many countries the shelf-life unrefrigerated is much longer than 18 months. This leads Thyroid Australia to question the TGA's approach to remedying potency issues with thyroxine. Addressing the matter by introducing refrigeration places the burden on patients.

Due to thyroxine, hypothyroidism is a readily treatable condition. It enables affected individuals to lead very close to normal lives. This change moves hypothyroidism from a condition that can be easily lived with, to a condition that impinges upon everyday life. In particular, it places limits on travel and spontaneity. We hope that refrigeration is only an interim measure until a more viable long-term solution is found.

\section{Gail Pascoe}

President, Thyroid Australia

Melbourne

\section{Dr Leonie Hunt, Assistant Secretary, Drug Safety \& Evaluation} Branch, Therapeutic Goods Administration, comments:

The Therapeutic Goods Administration has been working with the manufacturer and sponsors of thyroxine tablets to review the potency of the tablets throughout their shelf-life. There have been a number of consumer complaints about apparent lack of potency of thyroxine tablets over time. It is apparent that these tablets do not maintain their full potency if stored at room temperature.

For this reason it has been considered necessary to change recommended storage conditions of the tablets so they are now recommended to be stored in the refrigerator. It is essential that there be no significant variability in the potency of tablets either within any one bottle of tablets or between successive bottles of tablets. Refrigerated storage will assist in this endeavour.

The shelf-life of a medicine in any country will depend on a number of factors including the manufacturing within that country, room temperature conditions and factors related to the final formulation sold in the market place. What is important is that the shelf-life and storage conditions chosen for a market place result in the brands in that market place having reliable stability and potency over time.

\section{Editorial note:}

Sigma Pharmaceuticals, the manufacturer of thyroxine tablets, did not wish to add to the discussion.

\section{Off-label prescribing}

Editor, - Roger Goucke calls for Australian Prescriber to clarify the situation with regard to off-label prescribing (Aust Prescr 2004;27:82-3). NSWTherapeutic Advisory Group (NSWTAG)* has recently released a discussion paper to guide clinicians, policy makers and funders of health care in systematically evaluating the appropriateness of medicines proposed for off-label use.

In calling for clarification, Dr Goucke focuses his concerns on the legal issues associated with off-label use of medicines. Neither the Therapeutic Goods Administration in Australia nor the Food and Drug Administration in the USA ${ }^{1}$ regulate the use (including administration) of a medicine once it has been supplied by a product sponsor. Therefore off-label use by a practitioner (who was not a sponsor of the medicine) does not appear to be in breach of the Therapeutic Goods Act 1989 (Commonwealth) or the US Federal Food, Drug, and Cosmetic Act, 52 Stat. 1040. Although this has not been tested in an Australian court, it has been tested in US courts and found not to breach US legislation. ${ }^{2}$ In addition to legal issues, however, clinical and ethical issues, including patient consent, also need to be considered in any decision to prescribe medicines off-label. The NSW TAG Discussion Paper highlights these issues and provides a systematic approach to addressing them. The paper may be accessed on NSWTAG's web site www.nswtag.org.au

* NSWTAG is an independent, incorporated association of clinical pharmacologists, pharmacists and clinicians committed to promoting quality use of medicines in public hospitals and the wider community.

Maria Kelly

Executive Officer

New South Wales Therapeutic Advisory Group (NSWTAG)

Madlen Gazarian

Senior Lecturer, School of Women's and Children's Health University of New South Wales

Paediatric Clinical Pharmacologist and Rheumatologist Sydney Children's Hospital, Randwick

John McPhee

Legal Academic

Honorary Associate and Honorary Senior Lecturer

Centre for Values, Ethics and Law in Medicine

University of Sydney

\section{References}

1. Blum RS. Legal considerations in off-label medication prescribing. Arch Intern Med 2002;162:1777-9.

2. Buckman Co. v. Plaintiffs' Legal Committee. 531 U.S. 341 (2001). 